\title{
Differences in the Definitions Used for Esophageal and Gastric Diseases in Different Countries
}

\author{
Endoscopic Definition of the Esophagogastric Junction, the Precursor of Barrett's \\ Adenocarcinoma, the Definition of Barrett's Esophagus, and Histologic Criteria for \\ Mucosal Adenocarcinoma or High-Grade Dysplasia
}

\author{
Kaiyo Takubo a, b Michael Vieth ${ }^{b}$ Junko Aida ${ }^{a}$ Motoji Sawabe ${ }^{a}$ \\ Yoichi Kumagai $^{c}$ Yoshio Hoshihara ${ }^{d}$ Tomio Arai ${ }^{a}$ \\ ${ }^{a}$ Research Team for Geriatric Pathology, Tokyo Metropolitan Institute of Gerontology and Department of \\ Pathology, Tokyo Metropolitan Geriatric Hospital, Tokyo, Japan; ${ }^{b}$ Institute of Pathology, Klinikum Bayreuth,

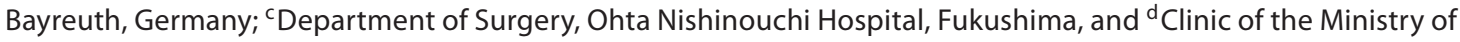 \\ Economy, Trade and Industry, Tokyo, Japan
}

\section{Key Words}

Barrett's esophagus • Esophagus, columnar-lined ·

Esophagogastric junction - Mucosa, intestinal-type, cardiac-type $\cdot$ Dysplasia, high-grade $\cdot$ Mucosal carcinoma

\begin{abstract}
Background: Definitions and opinions in the field of gastroenterology vary widely in different countries. Methods: Here we discuss four such important differences: the definition of the esophagogastric junction (EGJ), the possible precursor of Barrett's adenocarcinoma, the definition of Barrett's esophagus (BE), and the histologic criteria for mucosal adenocarcinoma. In addition, we consider which definitions and opinions might be valid and practical. Results: There are two different endoscopic definitions of the EGJ. Our research on German subjects has indicated that many small Barrett's adenocarcinomas may arise not in the intestinal-type but in the cardiac-type mucosa. If an area of columnar-lined esophagus (CLE) is only partially involved by intestinal metaplasia,
\end{abstract}

then the latter cannot always be demonstrated in biopsy specimens. Therefore, we do not think that a definition of BE as CLE with histologic intestinal metaplasia is practical. Data from the literature have shown that many cases of highgrade dysplasia (HGD) progress to carcinoma within a very short time, and in most such cases the carcinoma has been underdiagnosed in biopsy specimens as HGD. Conclusion: With regard to the definitions and opinions, an exchange of views between gastroenterologists in North America, Europe, and Japan would be desirable.

Copyright $\odot 2009$ S. Karger AG, Basel

\section{Introduction}

International meetings and medical journals enable medical doctors to exchange opinions very easily. However, definitions, concepts and opinions in the field of gastroenterology vary widely in different countries [1-5]. With regard to the esophagus and stomach in particular,

\section{KARGER}

Fax +41613061234 E-Mail karger@karger.ch www.karger.com
(C) 2009 S. Karger AG, Base

0012-2823/09/0804-0248\$26.00/0

Accessible online at:

www.karger.com/dig
Kaiyo Takubo

Research Team for Geriatric Pathology

Tokyo Metropolitan Institute of Gerontology

Sakae-cho 35-2, Itabashi-ku, Tokyo 173-0015 (Japan)

Tel. +81 33964 3241, Fax +81 33579 4776, E-Mail takubo@ tmig.or.jp 


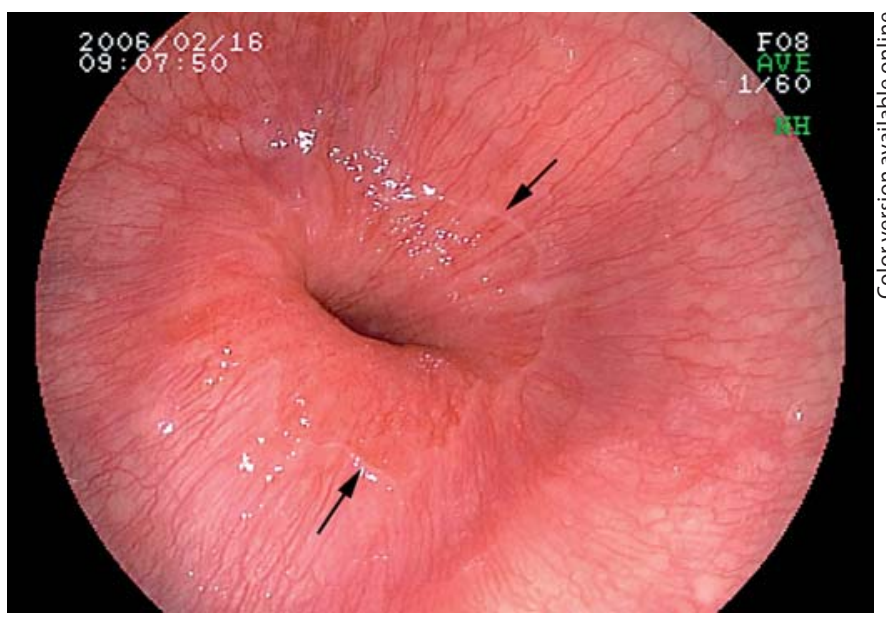

Fig. 1. Palisade longitudinal vessels in the columnar-lined esophagus (CLE). Palisade vessels are seen in both the squamous-lined and columnar-lined esophagus. In this case, a diagnosis of CLE can be made by endoscopy alone. Arrows = Squamocolumnar junction.

there are clear differences in the endoscopic definition of the esophagogastric junction (EGJ), the original or background mucosa of Barrett's adenocarcinoma (BA), the definition of Barrett's esophagus (BE), and the histologic criteria for high-grade dysplasia or well-differentiated adenocarcinoma with early invasion in the esophagus and stomach. Here we discuss these differences in terms of their practical applications.

\section{Endoscopic Definition of the EGJ}

\section{Upper Limit of Gastric Mucosal Folds or Lower Limit}

of Palisade Longitudinal Vessels

There has been no clear consensus among workers in different countries regarding the definition of the EGJ microscopically, macroscopically or endoscopically, although short-segment columnar-lined esophagus (CLE) has received a good deal of attention in recent reports. Precise definitions of the endoscopic features of the EGJ are essential before an accurate diagnosis of CLE can be made endoscopically.

Gastroenterologists in North America and Europe support the definition of the EGJ as being at the proximal margin of the gastric mucosal folds [6, 7]. In Japan, however, the EGJ is defined endoscopically as the lower limit of the palisade vessels [8-12]. This definition was endorsed by the Japan Esophageal Society in 2000 [8]. Histologically, large veins, $>100 \mu \mathrm{m}$ in diameter, are ob- served much more frequently in the lamina propria of the lower esophageal sphincter than in the middle and upper esophagus, and are considered to be the palisade vessels detected endoscopically [13]. They are also seen in salmon pink metaplastic columnar mucosa upon endoscopy (fig. 1). Therefore, in Japan, when palisade vessels are seen through the metaplastic columnar epithelium, a diagnosis of CLE can be made by endoscopy alone [8]. Most US and European authors [6] have considered this Japanese definition as not infallible, because distinguishing these vessels from other vascular patterns is sometimes difficult and palisade vessels cannot be adequately visualized in all patients. Furthermore, it has been reported that palisade vessels are not always evident in Western patients. In particular, US and European authors have reported that palisade vessels cannot always be observed upon endoscopy in patients with minimal-change esophagitis [9], characterized endoscopically by a mucosal cloudy whiteness and redness at deep inspiration [14, 15], gastroesophageal reflux disease (GERD), CLE, and BE. In such cases in Japan, proton pump inhibitor therapy is recommended before endoscopic examination to reveal the presence of palisade vessels. Our own observations have shown that proton pump inhibitor therapy results in a clear epithelium with easily visualized palisade vessels.

The incidences of GERD, BE, and BA are all still low in the Japanese population. Hoshihara and Kogure [12] reported that palisade vessels were visible in $98 \%$ of 905 Japanese subjects, whereas Western and Japanese endoscopists were able to observe palisade vessels in 88 and $89 \%$ of 82 US cases, respectively [16]. Therefore, Japanese gastroenterologists are able to observe palisade vessels more clearly in Japanese patients. The differences in the intention to visualize palisade vessels between US, European, and Japanese gastroenterologists and in the definition of the EGJ may be attributable to differences in the incidence of minimal-change esophagitis between Western and Japanese populations.

During endoscopic examination, the squamocolumnar junction (SCJ) is seen to move slightly with inspiration and expiration. The CLE should be scrutinized during deep inspiration in order to correctly determine the lower limit of the palisade vessels. For this reason it is impossible to check the location of the lower limit of the palisade vessels in patients under anesthesia. In North America and Europe endoscopy is frequently performed under anesthesia, whereas in Japan it is usually performed without anesthesia. 


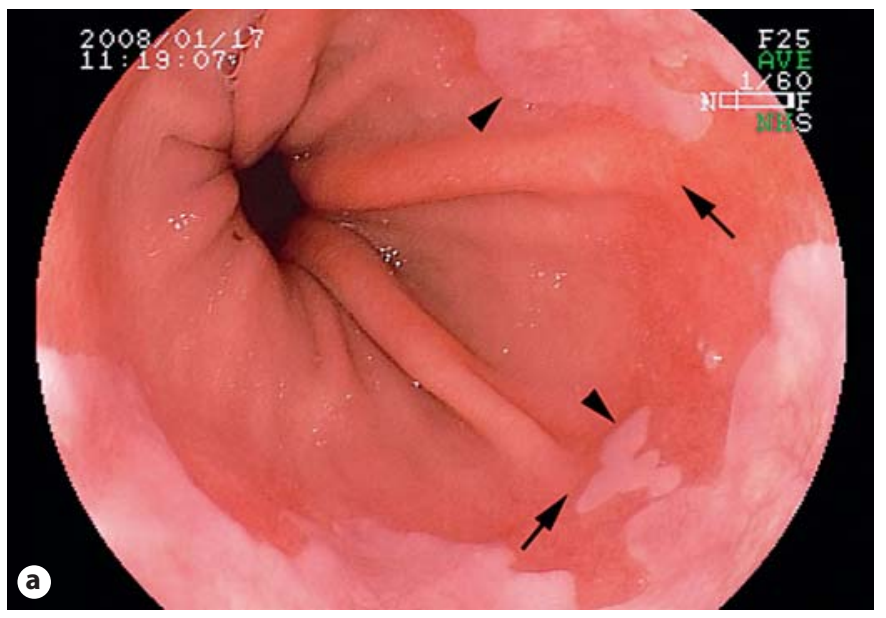

Fig. 2. Endoscopic appearance of the upper end of the gastric mucosal folds at the esophagogastric junction in a patient with Barrett's esophagus. The upper limit shows considerable up and down movement, depending on the volume of air in the esophagus. a When a small volume of air is present in the esophagus, the up-

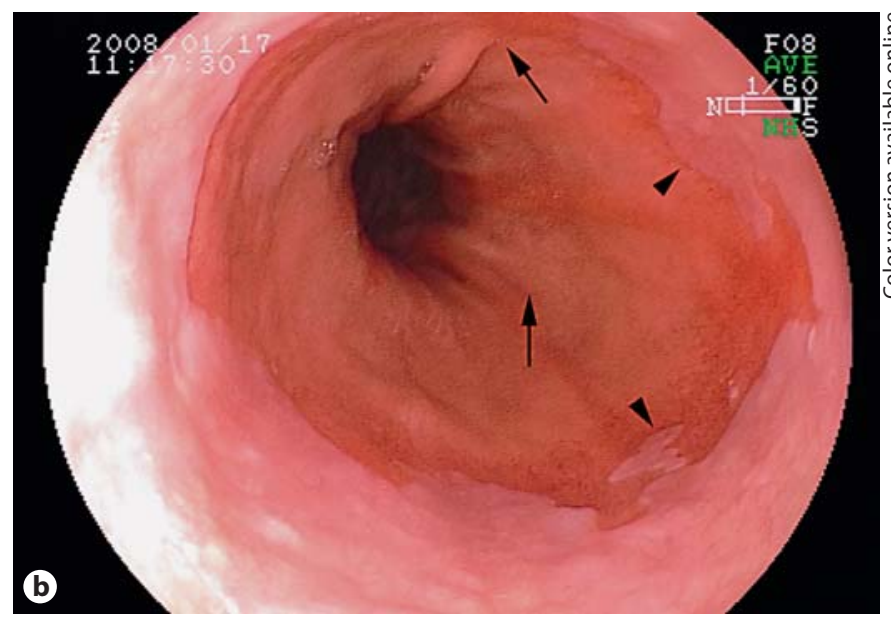

per end of the mucosal folds (arrows) extends up to or beyond the level of the lower end (arrowheads) of the squamous epithelium. b When a large volume of air is present in the esophagus, the upper end of the mucosal folds (arrows) is below the level of the lower end (arrowheads) of the squamous epithelium.
Respiration-Associated Movement of the Upper End of Gastric Mucosal Folds

Many Japanese endoscopists have considered that the US definition of the EGJ is imprecise, as the upper limit of the gastric folds is not located at a constant position and shows considerable up and down movement depending on the volume of air in the esophagus (fig. 2). Moreover, on deep inspiration, the upper end of the folds moves down (fig. 3). Therefore, apart from a few authors [17], most Japanese endoscopists believe that the lower end of the palisade vessels is a more suitable definition of the EGJ than the upper limit of the gastric mucosal folds.

\section{Lower Limit of Palisade Longitudinal Vessels and SCJ}

Preoperative endoscopy in a group of 42 Japanese subjects (mean age 62.9 years) with esophageal squamous cell carcinoma using still images revealed that, based on the Japanese criteria, CLE was seen in 59.5\%. In the resected specimens, the distal limit of the palisade vessels was lower than the SCJ in $95.2 \%$ of cases [18]. On the basis of the Japanese criteria, almost all of the patients had short-, or ultrashort-segment CLE. However, the maximal extent (length) of columnar metaplasia, corresponding to the ' $M$ ' value in the Prague $C \& M$ Criteria [6], was small and varied from 0 to 19 (mean 5.6) $\mathrm{mm}$.

An exchange of views between gastroenterologists in North America, Europe, and Japan would be desirable.

\section{Is the Lower Segment of the Esophagus Lined by} Columnar Epithelium?

The distance between the EGJ and the SCJ on macroscopic examination at autopsy has been reported in two articles. Bombeck et al. [19] reported that, in 21 autopsy cases, this distance ranged from 5 to 21 (mean 11) $\mathrm{mm}$, whereas we reported a range of 0 (14 cases) to 10 (mean 3) $\mathrm{mm}$ in 50 Japanese cases [9]. In the latter study, the EGJ was defined as the line between the angles of the opened esophagus and the greater curvature of the stomach. The definition of the EGJ used by Bombeck et al. [19] (the point of the esophagus flaring out into the stomach) was essentially similar to ours. The results indicate that the incidence of short-segment CLE is higher in Western countries than in Japan. In Japan, it is considered that the EGJ coincides with the SCJ, as the distance between them is frequently $0 \mathrm{~mm}$ based on our study of autopsy cases. Thus, it may be possible to define the EGJ as the SCJ. Shimoda et al. [20] also reported that the normal EGJ almost matched the straight (not zigzag) line of the SCJ, and that the EGJ coincided with the SCJ in most Japanese individuals. When the EGJ is defined as the lower limit of the palisade vessels endoscopically, or as the line connecting the angle of the opened esophagus and the greater curvature of the stomach macroscopically, the distal $2-3 \mathrm{~cm}$ of the esophagus is usually lined by squamous epithelium in Japanese subjects. 

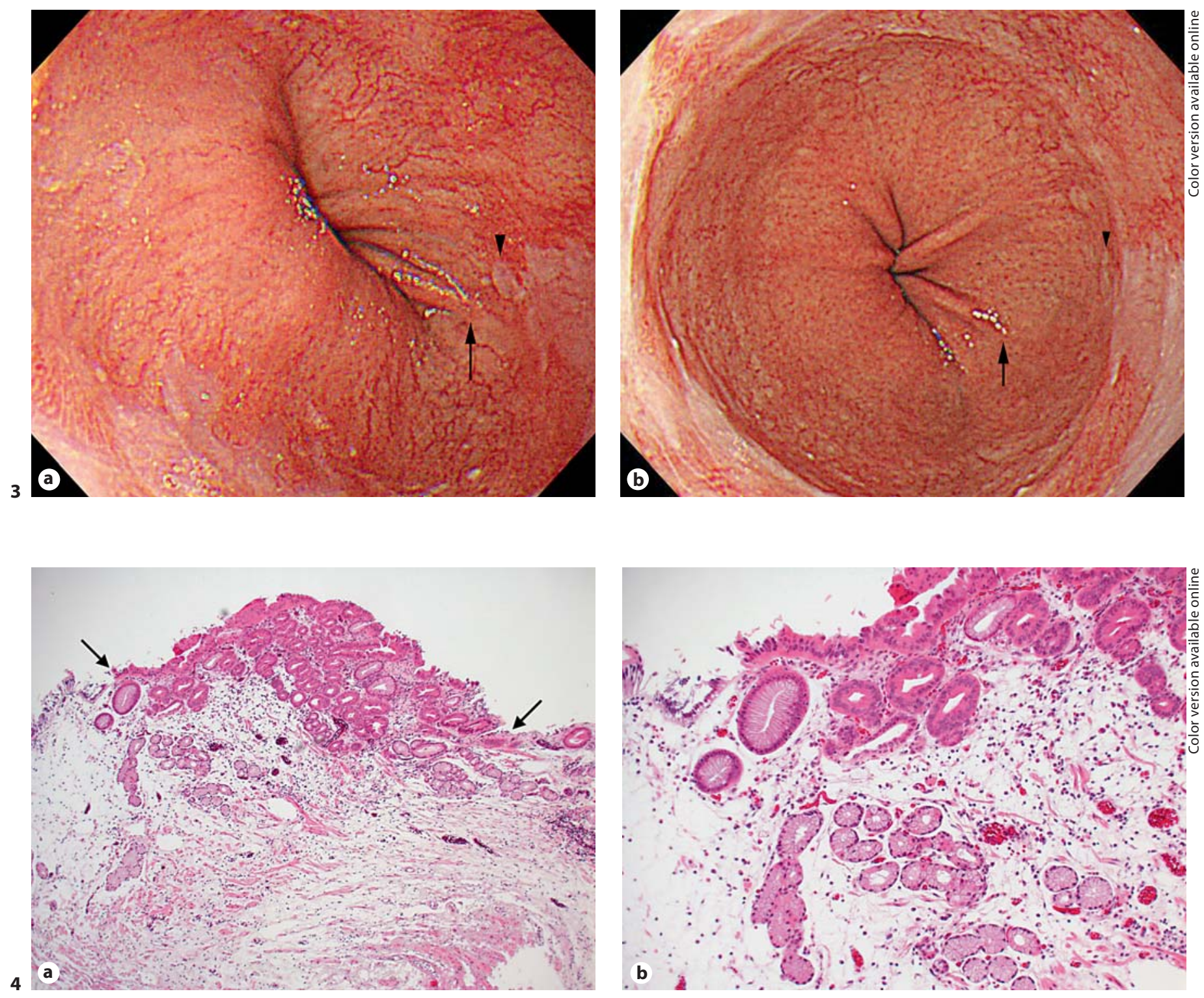

Fig. 3. Endoscopic appearance of the upper end of the gastric mucosal folds at the esophagogastric junction in a patient with Barrett's esophagus. a At expiration, the upper end (arrow) of the gastric mucosal folds reaches the same level as the lower end (arrowhead) of the squamous epithelium. b In deep inspiration, the esophagus is stretched and the EGJ becomes wider than at expiration, with the upper end of the folds moving downwards. There is a considerable distance between the upper (arrow) and lower (arrowhead) ends of the squamous epithelium.

Fig. 4. Barrett's adenocarcinoma (or high-grade or low-grade dysplasia by the WHO criteria), $1.5 \mathrm{~mm}$ in size. a The lesion is located in the area between the arrows. b, $\mathbf{c}$ In close-up views, it is surrounded by cardiac-type mucosa with some parietal cells (also known as oxyntocardiac mucosa). No goblet cells are evident. Five pathologists among the present authors agreed with the diagnosis of a well-differentiated adenocarcinoma.

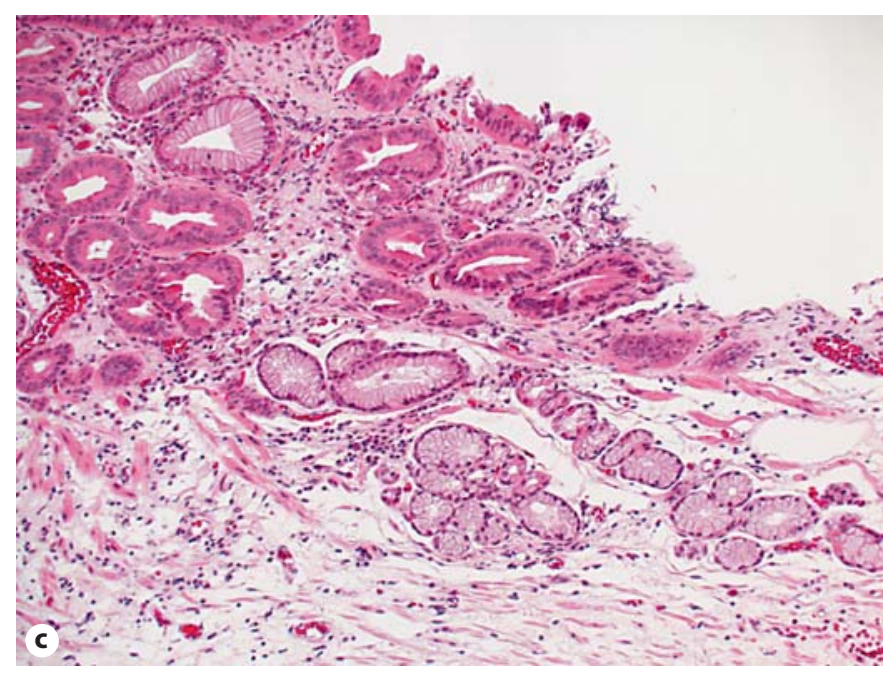


Table 1. Background mucosa of EGJ adenocarcinoma

\begin{tabular}{lcccc}
\hline Reference & $\mathrm{n}$ & $\begin{array}{l}\text { Mean } \\
\text { tumor } \\
\text { size, cm }\end{array}$ & $\begin{array}{l}\text { IM } \\
\%\end{array}$ & $\begin{array}{l}\text { Cardiac } \\
\text { mucosa } \\
\%\end{array}$ \\
\hline Haggitt et al. [24], 1978 & 12 & & 75 & 100 \\
Clark et al. [32], 1994 & 31 & 3.5 & 42 & \\
Cameron et al. [33], 1995 & 24 & 6.0 & 42 & \\
Van Sandick et al. [35], 2000 & 12 & 2.3 & 100 & \\
Ruol et al. [23], 2000 & 6 & 2.0 & 69 & \\
Cameron et al. [34], 2002 & 22 & 1.4 & 86 & \\
Tsuji et al. [29], 2004 & 54 & $<4$ & 38 & \\
Nunobe et al. [30], 2007 & 48 & 2.0 & 46 & \\
Takubo et al. [31], 2009 & $113^{\text {a }}$ & 0.69 & $<30$ & \\
\hline
\end{tabular}

EGJ = Esophagogastric junction; IM = intestinal-type mucosa.

a Showing endoscopic and histologic evidence of an esophageal origin.

\section{Precursor of BA}

\section{Histogenetic Studies}

The mucosa in CLE has been classified into fundic, junctional (cardiac) and specialized columnar (intestinal) types in what was thought to be the order of arrangement from the distal end [21]. However, in short-segment, and even long-segment CLE [22], these three types tend to be admixed, and there is no clear zonal pattern in many cases of BE. Nowadays a more mosaic form of distribution of different types of epithelium has been proposed.

It is widely accepted that intestinal-type mucosa in the CLE is the probable common precursor of adenocarcinoma [23]. Many publications focusing on the background mucosa of BA have maintained that adenocarcinoma arises in intestinal-type mucosa with goblet cells in the CLE. Milestones in the literature on this subject by Haggitt et al. [24], Skinner et al. [25], Reid and Weinstein [26], Hamilton and Smith [27], and Spechler and Goyal [28] have considered that intestinal metaplasia in particular predisposes patients to cancer development, and this seems to have become the prevailing view among upper gastrointestinal tract specialists. However, Japanese pathologists have frequently reported that the background mucosa adjacent to BA in Japanese subjects is of the cardiac rather than intestinal type. Tsuji et al. [29] and Nunobe et al. [30] reported incidences of intestinal-type mucosa with BA of 38 and $46 \%$, respectively, among Japanese subjects. In our laboratory, 6 of 8 Japanese cases of primary adenocarcinoma of the esophagus had cardiactype mucosa (fig. 4). Therefore, we have considered for a long time that this phenomenon is peculiar to Japan, and differs from the prevailing trend in North America and Europe.

We have reviewed a series of endoscopically resected samples of very small BAs (mean diameter $6.6 \mathrm{~mm}$ ) [31]. This study was a retrospective histopathologic one to clarify the nature of the background mucosae. Therefore, it is possible that preexisting small foci of intestinalor cardiac-type mucosa may have been completely destroyed by carcinomatous invasion, even though the tumors were very small. We found that only $22.8 \%$ of the esophageal adenocarcinomas $(n=113)$ were surrounded by intestinal-type mucosa, and that $70.8 \%$ were adjacent to cardiac-type mucosa. Seven tumors were surrounded by cardiac- and intestinal-type mucosae. These data are in accordance with the findings of previous Japanese studies $[29,30]$. We reviewed 9 articles on the background of BA $[23,24,29,30,32-35]$ and found that the BAs were very large and advanced, and that the incidence of intestinal-type mucosa adjacent to or surrounding the carcinoma varied widely from 30 to $100 \%$ (table 1). The first histogenetic study of BA was reported by Haggitt et al. [24] who found that 9 of 12 BAs were located adjacent to intestinal-type mucosa and that all 12 were also adjacent to cardiac-type mucosa. Although the original mucosa was found to be histogenetically unequivocal in view of the small sizes of the carcinomas, on the basis of table 1 no relationship between tumor size and background is evident. We used a histogenetic method similar to that of many previous reports. However, we were unable to demonstrate whether the background mucosa of BA was the intestinal type.

As to the risk of developing BA, in long-segment CLE the risk of cancer increases with the length of the BE [36]. However, May et al. [37] found that short-segment CLE was also associated with a high cancer risk: more than $40 \%$ of BAs were found in short-segment CLE. Schnell et al. [38] also emphasized that patients with short-segment CLE should be considered at risk and followed in the same way as their counterparts with long-segment BE. If adenocarcinomas nearly always arise in intestinal-type mucosa in cases of long-segment CLE, then one would expect to see more of such tumors in the proximal zone of the CLE because this is where intestinal-type mucosa is believed to be found more often [21]. However, this does not seem to be the case, suggesting that BA might occur not only in intestinal mucosa but also in cardiac-type mucosa. 


\section{Molecular Pathologic Studies}

It has not been determined whether the intestinal type of CLE is the only epithelium susceptible to the action of undetermined carcinogenic molecules in the gastric refluxate $[39,40]$. It has been reported that DNA content abnormalities occurred with equal frequency and extent in both CLE with and without goblet cells [41].

Further investigations of carcinogenesis in BA, including histogenetic analysis of very small carcinomas (smaller than those in our previous study [31]) and molecular studies, are needed.

\section{Definition of BE}

As mentioned above, recent histogenetic and molecular studies have not indicated that intestinal-type mucosa in the CLE is the probable common precursor of adenocarcinoma.

Biopsy specimens from the CLE often do not show intestinal metaplasia $[42,43]$. To demonstrate intestinaltype mucosa by biopsy, multiple specimens (more than 8 ) are often needed [44]. Therefore, at least for random biopsy sampling, it seems impractical to define BA purely on the basis of metaplastic columnar-lined mucosa with goblet cells. Based on a retrospective review study including 712 subjects with follow-up times ranging from 8 to 20 years, Kelty et al. [45] reported that patients who have CLE on biopsy without intestinal metaplasia have a similar cancer risk as those with intestinal metaplasia. A prospective cohort study by the UK National Barrett's Oesophagus Registry (2008) revealed no significant difference in the rate of development of neoplasia between patients with and without intestinal metaplasia at first endoscopy for a series of 1,751 patients with a mean follow-up period of 3.5 years [46]. The definition of BE differs between Japan, the UK, Germany and the USA. In Japan [8] and the UK [47], BE is defined simply as metaplastic CLE that is macroscopically recognizable. In Germany and the USA, however, it is defined as the metaplastic replacement of any length of the esophageal epithelium that can be recognized at endoscopy and that is confirmed by biopsy of the tubular esophagus to show specialized intestinal metaplasia (i.e. CLE with goblet cells), excluding intestinal metaplasia of the gastric cardia [48]. If intestinal metaplasia only partially involves an area of CLE then it may not always be seen in biopsy specimens [42-44, 46]. Moreover, a close relationship between BA and intestinal-type mucosa has not always been demonstrated, as noted above. Also, it has not been demon- strated that intestinal-type mucosa is the only type which is susceptible to the action of carcinogens present in gastric juice $[39,40]$.

Therefore, defining BE as CLE with intestinal metaplasia on the basis of random biopsy specimens and surgical specimens is not practical. Thus, the practical application of the definition of BE used in Germany and the USA is no better than that used in Japan and the UK.

\section{Mucosal Adenocarcinoma and High-Grade Dysplasia in CLE, BE, and the Stomach}

\section{Difference of Mucosal Adenocarcinoma and High-Grade Dysplasia}

There are large differences between North American, European and Japanese pathologists with regard to the criteria used for histologic diagnosis of dysplasia (intraepithelial neoplasia) and adenocarcinoma without clear invasion into the lamina propria of the esophagus $[9,49]$, stomach (fig. 5, 6) and duodenum. These differences apply more to biopsies than to resection specimens. Reported incidences of high-grade dysplasia and lowgrade dysplasia were $7.2-0.4 \%$ [50] and $67.2-1.1 \%$ [51] in consecutive biopsy series. Jass [2] clarified philosophical discrepancies between East and West, and noninvasive high-grade dysplasia will continue to be regarded as carcinoma in situ or superficial carcinoma, a lesion that has already acquired the potential to invade even if the potential is not currently realized and/or proven in Japan, whereas in many countries the same term will usually imply a lesion that has not yet achieved invasive potential and might never do so. This is not only a difference in terminology; the histology of high-grade dysplasia is not equal to that of adenocarcinoma without stromal invasion in Japan.

Histologic photographs labelled as high-grade dysplasia and some as low-grade dysplasia in textbooks $[52,53]$ of surgical pathology published in North America and Europe would be diagnosed as clearcut cases of well to moderately differentiated tubular adenocarcinoma with or without stromal invasion by Japanese pathologists [9], and also by some experienced German pathologists. Fibrosis, small glands of adenocarcinoma and small nests consisting of a few cancer cells are considered to be evidence of stromal invasion (fig. 6).

Japanese pathologists, and some German pathologists, need not diagnose high-grade dysplasia or intraepithelial neoplasia in lesions of the CLE $[54,55]$ and stomach [56]. Most Japanese pathologists, and the groups of Vieth and 


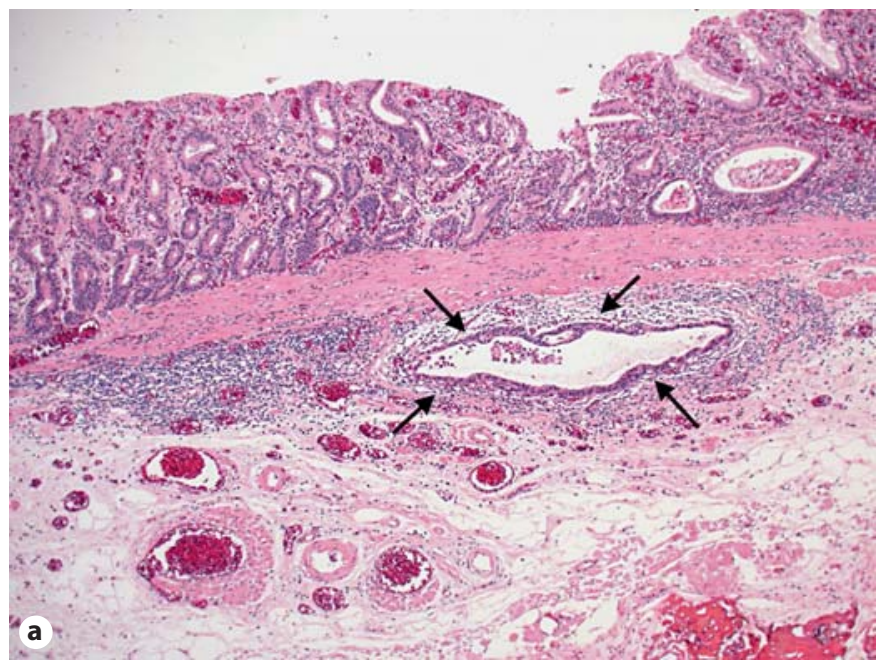

Fig. 5. A wide area of well-differentiated adenocarcinoma of the stomach without stromal invasion in the mucosa (high-grade dysplasia by the WHO criteria). The tumor size was $15 \times 10 \mathrm{~mm}$. a Although the mucosal component does not show clear stromal

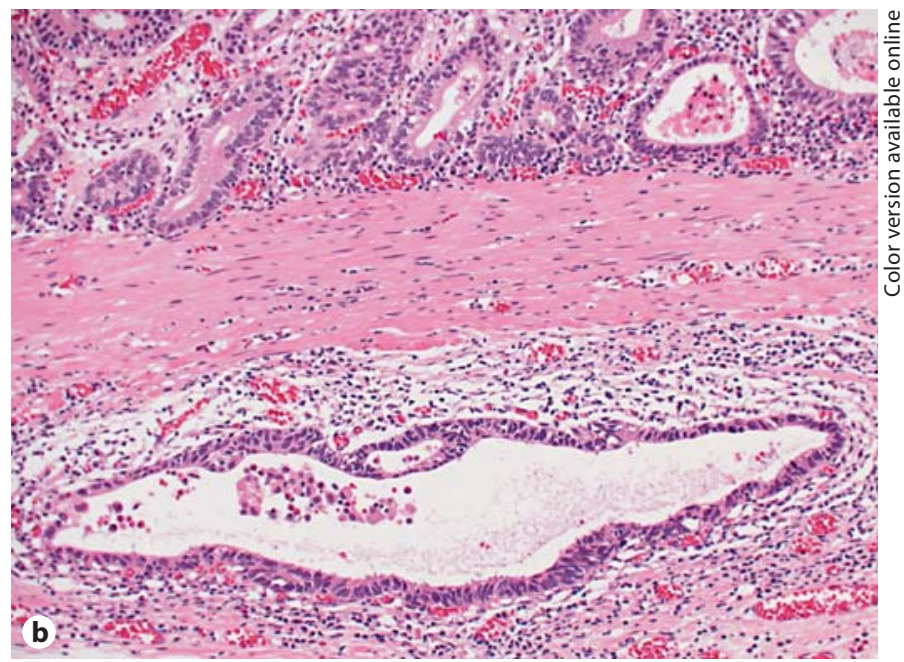

invasion, submucosal invasion (arrows) beneath the lamina muscularis mucosa is evident. b Close-up view, showing a focus of stromal invasion with fibrosis in the submucosa.

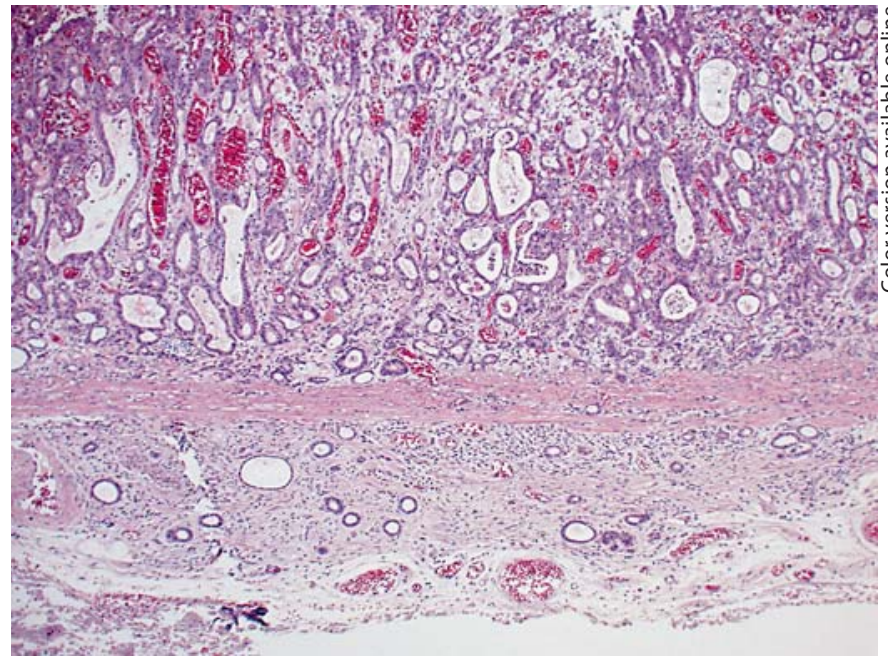

Fig. 6. A wide area of well- to moderately-differentiated adenocarcinoma of the stomach with stromal invasion in mucosa with submucosal invasion (adenocarcinoma by the WHO criteria). The tumor size was $48 \times 30 \mathrm{~mm}$. Stromal reaction (fibrosis) and small cancer nests are evident in the lamina propria mucosae and submucosa.

Stolte [56] and Borchard [57] in Germany, agree that the term tubular adenocarcinoma can and should be used for lesions in the esophagus, stomach, and duodenum that have the cytologic features of cancer but lack a desmoplastic stromal reaction, or nests or single tumor cells. How-

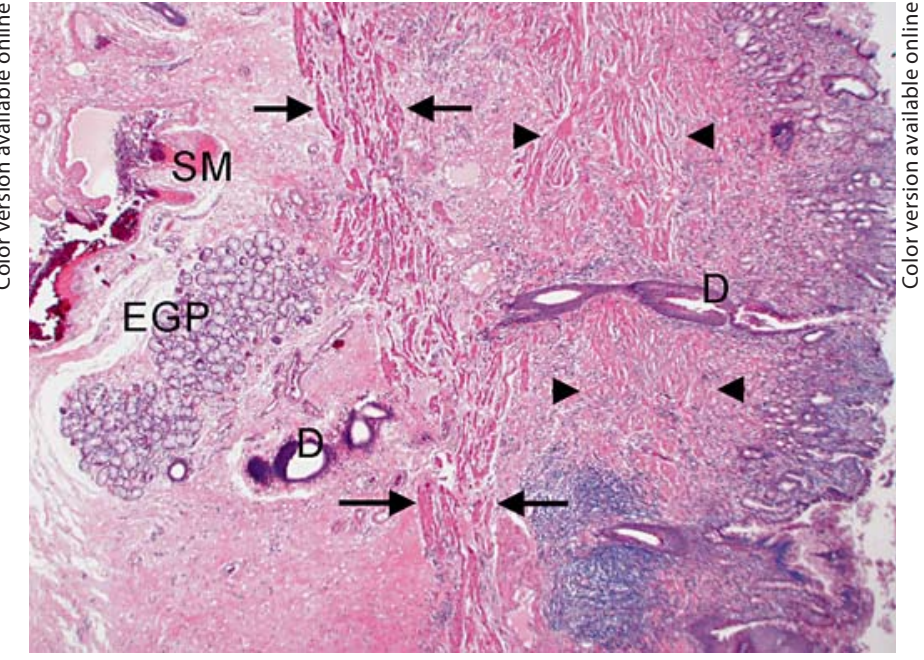

Fig. 7. Double muscularis mucosae of the columnar-lined esophagus. A segment of columnar-lined esophagus has a double muscularis mucosae. Arrows = Deep muscularis mucosae; arrowheads = superficial muscularis mucosae; EGP = esophageal gland proper in the submucosa $(\mathrm{SM}) ; \mathrm{D}=$ duct of esophageal gland proper.

ever, tubular adenocarcinoma is a concept including both noninvasive and invasive malignancy.

Clear invasive adenocarcinoma often coexists with intramucosal spreading adenocarcinoma in the esophagus and stomach. Mucosal adenocarcinomas show histologic 
features similar to those of the intramucosal components adjacent to deeply invasive carcinomas. In North American and European literature, BA is said to arise from high-grade dysplasia. However the view of Japanese pathologists is that it is a simple process for an invasive carcinoma to have an intramucosal component, especially since many follow-up studies of high-grade dysplasia in biopsies have turned out to represent underdiagnosed adenocarcinomas [56].

\section{Estimation of Invasion Depth, rather than Biopsy}

Histology, as an Indication for Endoscopic Resection or Major Surgery

Some pathologists frequently maintain that if they use 'well-differentiated tubular adenocarcinoma' as a histologic criterion instead of 'high-grade dysplasia' then endoscopic resection (ER) is not considered as a treatment option, and that immediate major surgical resection should be considered. This approach seems difficult to justify, because biopsy specimens cannot be used to estimate invasion depth, although high-grade dysplasia (also known as well-differentiated tubular adenocarcinoma) does not show stromal invasion. It should also be noted that, even if the histologic diagnosis of a biopsy specimen is adenocarcinoma with definite stromal invasion, it does not always necessarily indicate a need for major surgery. Again, we wish to stress that the choice between major surgery with lymph node dissection and ER should be made on the basis of an estimation of tumor depth.

High-grade dysplasia frequently has a component of invasive carcinoma in the submucosa. Therefore highgrade dysplasia should not be treated by radiofrequency ablation, but by ER, in order to obtain a specimen for histologic examination. Knowledge of invasion depth is needed for additional therapy, even if the biopsy diagnosis is high-grade dysplasia.

Lymph Node Metastasis and a New Subclassification of Depth of Invasion by Mucosal BA

Incidences of lymph node metastasis in mucosal BAs have been reported in 11 studies from Western countries, of which 8 stated that there was no nodal involvement [55]. The incidences of nodal metastasis reported in the other 3 studies were $1.3,3.7$, and $10.3 \%$.

An important issue in mucosal BA is the presence of a double muscularis mucosae (fig. 7) [58]. These layers, which can be seen in every case of CLE, make it difficult to define the exact depth of tumor invasion. The clinical relevance of this issue is undecided. There are, however, two proposals from the Netherlands and Germany. Vieth and Stolte [55] proposed a subdivision into $\mathrm{m} 1$ (within the lamina propria), $\mathrm{m} 2$ (infiltration of the superficial muscularis mucosae), m3 (infiltration of the layer between the superficial and deep muscularis mucosae), and $\mathrm{m} 4$ (infiltration of the deep muscularis mucosae). Westerterp et al. [59], proposed a subdivision into $\mathrm{m} 1$ (within the mucosa), $\mathrm{m} 2$ (infiltration of the layer between the superficial and deep muscularis mucosae), and $\mathrm{m} 3$ (infiltration of the deep muscularis mucosae). Fortunately, lymphatic vessel permeation is rare in cases of mucosal adenocarcinoma in the esophagus [55]. Further study is needed to clarify the relationship between the depth of invasion ( $\mathrm{m} 1-\mathrm{m} 4$ by Vieth and Stolte [55], and $\mathrm{m} 1-\mathrm{m} 3$ by Westerterp et al. [59]) and lymph node metastasis in order to decide the optimum therapy for early adenocarcinoma, including ER or major surgery. Further study is also needed to establish the prognostic significance of the subclassification of invasion depth (m1-m3) in esophageal early squamous cell carcinoma in terms of lymph node metastasis [5]. In fact, most early well-differentiated lesions without risk factors such as lymphatic vessel permeation will never metastasize, regardless of whether the preference is for $\mathrm{m} 1-\mathrm{m} 4$ or $\mathrm{m} 1-\mathrm{m} 3$.

\section{Conclusion}

This review has attempted to clarify the differences that exist among workers in different countries with regard to the clinical and pathologic issues related to the EGJ, CLE, BE, and high-grade dysplasia. With regard to the definition of the EGJ, we think that an exchange of views between gastroenterologists in North America, Europe, and Japan would be desirable. We also believe that the definition of BE should be CLE, and that high-grade dysplasia (which is diagnosed as well-differentiated adenocarcinoma by Japanese and some German pathologists) should not be diagnosed in the esophageal and gastric mucosa. Furthermore, we believe that the precursor of BA is not intestinal-type mucosa, but rather cardiactype mucosa. 


\section{References}

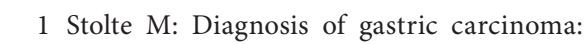
Japanese fairy tales or Western deficiency? Virchows Arch 1999;434:279-280.

$\checkmark 2$ Jass JR: Discrepancies between East and West. Cancer 2000;88:969-970.

3 Schlemper RJ, Itabashi M, Kato Y, Lewin KJ, Riddell RH, Shimoda T, Sipponen P, Stolte M, Watanabe H, Takahashi H, Fujita R: Differences in diagnostic criteria for gastric carcinoma between Japanese and Western pathologists. Lancet 1997;349:1725-1729.

-4 Schlemper RJ, Riddell RH, Kato Y, Borchard F, Cooper HS, Dawsey SM, Dixon MF, Fenoglio-Preiser CM, Flejou JF, Geboes K, Hattori $T$, Hirota $T$, Itabashi $M$, Iwafuchi $M$, Iwashita A, Kim YI, Kirchner T, Klimpfinger M, Koike M, Lauwers GY, Lewin KJ, Oberhuber G, Offner F, Price AB, Rubio CA, Shimizu M, Shimoda T, Sipponen P, Solcia E, Stolte M, Watanabe $\mathrm{H}$, Yamabe $\mathrm{H}$ : The Vienna classification of gastrointestinal epithelial neoplasia. Gut 2000;47:251-255.

$\checkmark 5$ Takubo K, Aida J, Sawabe M, Kurosumi M, Arima M, Fujishiro M, Arai T: Early squamous cell carcinoma of the oesophagus: The Japanese viewpoint. Histopathology 2007; 51:733-742.

-6 Sharma P, Dent J, Armstrong D, Bergman JJ, Gossner L, Hoshihara Y, Jankowski JA, Junghard $\mathrm{O}$, Lundell L, Tytgat GN, Vieth M: The development and validation of an endoscopic grading system for Barrett's esophagus: The Prague C \& M criteria. Gastroenterology 2006;131:1392-1399.

7 Lenglinger J, Eislier M, Wrba F: Update: Histopathology-based definition of gastroesophageal reflux disease and Barrett's esophagus. Eur Surg 2008;40:165-175.

8 Aoki T: Report of Research Committee on Definition of Barrett's Esophagus. Chiba, Japanese Society of Esophageal Diseases, 2000.

$\checkmark 9$ Takubo K, Arai T, Sawabe M: Structures of the normal esophagus and Barrett's esophagus. Esophagus 2003;1:37-47.

-10 Takubo K, Honma N, Aryal G, Sawabe M, Arai T, Tanaka Y, Mafune K, Iwakiri K: Is there a set of histologic changes that are invariably reflux associated? Arch Pathol Lab Med 2005;129:159-163.

-11 De Carvalho CAF: Sur l'angio-architecture veineuse de la zone de transition œsophagogastrique et son interprétation fonctionnelle. Acta Anat 1966;64:125-162.

12 Hoshihara Y, Kogure T: What are longitudinal vessels? Endoscopic observation and clinical significance of longitudinal vessels in the lower esophagus. Esophagus 2006;3: $145-150$.

-13 Takubo K, Aida J, Sawabe M, Arai T, Kato H, Pech O, Arima M: The normal anatomy around the oesophagogastric junction: a histopathologic view and its correlation with endoscopy. Best Pract Res Clin Gastroenterol 2008;22:569-583.
14 Kiesslich R, Kanzler S, Vieth M, Moehler M, Neidig J, Thanka Nadar BJ, Schilling D, Burg J, Nafe B, Neurath MF, Galle PR: Minimal change esophagitis: prospective comparison of endoscopic and histological markers between patients with non-erosive reflux disease and normal controls using magnifying endoscopy. Dig Dis 2004;22:221-227.

15 Vieth M: Structural abnormalities of endoscopy-negative reflux disease - real or perceived? Digestion 2008;78(suppl 1):24-30.

16 Kusano C, Kaltenbach T, Shimazu T, Soetikno R, Gotoda T: Can Western endoscopists identify the end of the lower esophageal palisade vessels as a landmark of esophagogastric junction? J Gastroenterol 2009;44:842846.

17 Amano Y, Ishimura N, Furuta K, Takahashi Y, Chinuki D, Mishima Y, Moriyama I, Fukuhara H, Ishihara S, Adachi K, Kinoshita Y: Which landmark results in a more consistent diagnosis of Barrett's esophagus, the gastric folds or the palisade vessels? Gastrointest Endosc 2006;64:206-211.

18 Ogiya K, Kawano T, Ito E, Nakajima Y, Kawada K, Nishikage T, Nagai K: Lower esophageal palisade vessels and the definition of Barrett's esophagus. Dis Esophagus 2008;21:645-649.

19 Bombeck CT, Dillard DH, Nyhus LM: Muscular anatomy of the gastroesophageal junction and role of phrenoesophageal ligament; autopsy study of sphincter mechanism. Ann Surg 1966;164:643-654.

20 Shimoda T, Nakanishi Y, Saka M: The recent advances and concept of Barrett's esophagus. I to Cho, Stomach and Intestine 2004;39: 1211-1222.

21 Paull A, Trier JS, Dalton MD, Camp RC, Loeb P, Goyal RK: The histologic spectrum of Barrett's esophagus. N Engl J Med 1976; 295:476-480.

22 Thompson JJ, Zinsser KR, Enterline HT: Barrett's metaplasia and adenocarcinoma of the esophagus and gastroesophageal junction. Hum Pathol 1983;14:42-61.

23 Ruol A, Parenti A, Zaninotto G, Merigliano S, Costantini M, Cagol M, Alfieri R, Bonavina L, Peracchia A, Ancona E: Intestinal metaplasia is the probable common precursor of adenocarcinoma in Barrett esophagus and adenocarcinoma of the gastric cardia. Cancer 2000;88:2520-2528.

24 Haggitt RC, Tryzelaar J, Ellis FH, Colcher H Adenocarcinoma complicating columnar epithelium-lined (Barrett's) esophagus. Am J Clin Pathol 1978;70:1-5.

25 Skinner DB, Walther BC, Riddell RH, Schmidt H, Iascone C, DeMeester TR: Barrett's esophagus. Comparison of benign and malignant cases. Ann Surg 1983;198:554565.
26 Reid BJ, Weinstein WM: Barrett's esophagus and adenocarcinoma. Annu Rev Med 1987; 38:477-492.

27 Hamilton SR, Smith RR: The relationship between columnar epithelial dysplasia and invasive adenocarcinoma arising in Barrett's esophagus. Am J Clin Pathol 1987;87:301312.

28 Spechler SJ, Goyal RK: The columnar-lined esophagus, intestinal metaplasia, and norman Barrett. Gastroenterology 1996;110: 614-621.

29 Tsuji N, Ishiguro S, Tsukamoto Y, Mano M, Kasugai T, Miyashiro I, Doki Y, Iishi H, Kudo M: Mucin phenotypic expression and background mucosa of esophagogastric junctional adenocarcinoma. Gastric Cancer 2004; 7:97-103.

30 Nunobe S, Nakanishi Y, Taniguchi H, Sasako M, Sano T, Kato H, Yamagishi H, Sekine S, Shimoda T: Two distinct pathways of tumorigenesis of adenocarcinomas of the esophagogastric junction, related or unrelated to intestinal metaplasia. Pathol Int 2007;57: 315-321.

-31 Takubo K, Aida J, Naomoto Y, Sawabe M, Arai T, Shiraishi H, Matsuura M, Ell C, May A, Pech O, Stolte M, Vieth M: Cardiac rather than intestinal-type background in endoscopic resection specimens of minute Barrett adenocarcinoma. Hum Pathol 2009;40:6574.

32 Clark GW, Smyrk TC, Burdiles P, Hoeft SF, Peters JH, Kiyabu M, Hinder RA, Bremner CG, DeMeester TR: Is Barrett's metaplasia the source of adenocarcinomas of the cardia? Arch Surg 1994;129:609-614.

33 Cameron AJ, Lomboy CT, Pera M, Carpenter HA: Adenocarcinoma of the esophagogastric junction and Barrett's esophagus. Gastroenterology 1995;109:1541-1546.

34 Cameron AJ, Souto EO, Smyrk TC: Small adenocarcinomas of the esophagogastric junction: association with intestinal metaplasia and dysplasia. Am J Gastroenterol 2002;97: 1375-1380.

35 van Sandick JW, van Lanschot JJ, ten Kate FJ, Offerhaus GJ, Fockens P, Tytgat GN, Obertop H: Pathology of early invasive adenocarcinoma of the esophagus or esophagogastric junction: implications for therapeutic decision making. Cancer 2000;88:2429-2437.

>36 Menke-Pluymers MB, Hop WC, Dees J, van Blankenstein M, Tilanus HW: Risk factors for the development of an adenocarcinoma in columnar-lined (Barrett) esophagus. The Rotterdam Esophageal Tumor Study Group. Cancer 1993;72:1155-1158.

37 May A, Gossner L, Pech O, Muller H, Vieth M, Stolte M, Ell C: Intraepithelial high-grade neoplasia and early adenocarcinoma in short-segment Barrett's esophagus (SSBE): curative treatment using local endoscopic treatment techniques. Endoscopy 2002;34: 604-610 
-38 Schnell TG, Sontag SJ, Chejfec G: Adenocarcinomas arising in tongues or short segments of Barrett's esophagus. Dig Dis Sci 1992;37:137-143.

-39 Lombard C: Controversies of the cardiac mucosa and Barrett's oesophagus. Histopathology 2006;49:97-98.

40 Chandrasoma P: Controversies of the cardiac mucosa and Barrett's oesophagus. Histopathology 2005;46:361-373.

41 Liu W, Hahn H, Odze RD, Goyal RK: Metaplastic esophageal columnar epithelium without goblet cells shows DNA content abnormalities similar to goblet cell-containing epithelium. Am J Gastroenterol 2009;104: 816-824.

42 Shepherd NA: Barrett's esophagus: its pathology and neoplastic complications. Esophagus 2003;1:17-29.

$\checkmark 43$ Coad RA, Shepherd NA: Barrett's oesophagus: definition, diagnosis and pathogenesis. Curr Diagn Pathol 2003;9:218-227.

-44 Harrison R, Perry I, Haddadin W, McDonald S, Bryan R, Abrams K, Sampliner R, Talley NJ, Moayyedi P, Jankowski JA: Detection of intestinal metaplasia in Barrett's esophagus: an observational comparator study suggests the need for a minimum of eight biopsies. Am J Gastroenterol 2007;102:11541161.
45 Kelty CJ, Gough MD, Van Wyk Q, Stephenson TJ, Ackroyd R: Barrett's oesophagus: intestinal metaplasia is not essential for cancer risk. Scand J Gastroenterol 2007;42:12711274.

46 Gatenby PA, Ramus JR, Caygill CP, Shepherd NA, Watson A: Relevance of the detection of intestinal metaplasia in non-dysplastic columnar-lined oesophagus. Scand J Gastroenterol 2008;43:524-530.

47 Playford RJ: New British Society of Gastroenterology (BSG) guidelines for the diagnosis and management of Barrett's oesophagus. Gut 2006;55:442.

48 Sampliner RE: Updated guidelines for the diagnosis, surveillance, and therapy of Barrett's esophagus. Am J Gastroenterol 2002; 97:1888-1895.

49 Takubo K: Barrett's esophagus and primary adenocarcinoma of the esophagus; in $\mathrm{Pa}$ thology of the Esophagus: An Atlas and Textbook. New York, Springer, 2007, pp 191211.

50 Vieth M, Stolte M: Barrett's esophagus and neoplasia: data from the Bayreuth Barrett's Archive. Gastroenterology 2002;122:590591.

51 Vieth M: Low-grade dysplasia in Barrett's esophagus - an innocent bystander? Contra. Endoscopy 2007;39:647-649.

52 Werner M, Flejou JF, Hainaut P: Adenocarcinoma of the Oesophagus. Lyon, IARC Press, 2000.
53 Rosai J: Esophagus, ed 9. St Louis, Mosby, 2004.

54 Vieth M, Kiesslich R: Distinction of highgrade intraepithelial neoplasia and invasive Barrett's adenocarcinoma. Esophagus 2006; 3:171-176.

55 Vieth M, Stolte M: Pathology of early upper GI cancers. Best Pract Res Clin Gastroenterol 2005;19:857-869.

56 Vieth M, Stolte M: Distinction of HighGrade Intraepithelial Neoplasia and Tubular Gastric Adenocarcinoma. Tokyo, Springer, 2005.

57 Borchard F: Forms and nomenclature of gastrointestinal epithelial expansion: what is invasion? (in German) Verh Dtsch Ges Pathol 2000;84:50-61.

58 Takubo K, Sasajima K, Yamashita K, Tanaka Y, Fujita K: Double muscularis mucosae in Barrett's esophagus. Hum Pathol 1991;22: 1158-1161.

59 Westerterp M, Koppert LB, Buskens CJ, Tilanus HW, ten Kate FJ, Bergman JJ, Siersema PD, van Dekken H, van Lanschot JJ: Outcome of surgical treatment for early adenocarcinoma of the esophagus or gastro-esophageal junction. Virchows Arch 2005;446: 497-504. 